DOI: 10.20472/TEC.2019.007.003

\author{
EMIR OMER EMRE \\ University of Exeter, United Kingdom
}

\title{
THE TRAINING PROCESS OF TEACHING ASSISTANTS WHO MOSTLY TEACH PUPILS WITH SEND IN MAINSTREAM CLASSROOMS
}

\begin{abstract}
:
Inclusive education has become increasingly valued every year over the past decade within the implementation of education. Regarding this, the training situations of Teaching Assistants (TAS) is gaining more importance when working with pupils with SEND (special educational needs and disabilities) in mainstream education classrooms. This proposed study is an exploration of the training factors that influence the role of TAs when teaching students with SEND in mainstream classrooms in England during their one-year training. I will adopt an interpretivist approach, using a multiple case study design to explore the degree of relationship between the training factors and the role implementation of TAs when teaching pupils with SEND in mainstream classrooms in England during an eight-month period.

This proposed multi-method study will feature 12 case studies, and each of those case studies will involve a trainee TA. By using the semi-structured interview and non-participant observation methods for each of the case studies, through this proposed study I am seeking to make a meaningful contribution to educational knowledge in different ways. My aim is to increase the understanding of the influence level of training on TAs' personal knowledge and professional skills. This should further our understanding of the connection between TAs' training and the quality, nature and differentiation of education in the classroom. I am also seeking to find out whether there is a gap between the training of TAs and the role requirements of TAs, regarding the teaching of students with SEND in mainstream classrooms.
\end{abstract}

\section{Keywords:}

Teaching Assistants, Teaching Asssistant Training, Inclusive Education, Inclusion, SEND, Special Educational Needs

JEL Classification: 129, D63 


\section{Introduction}

Inclusion is one of the most researched and controversial issues in academic literature within the context of formal education (Avramidis and Norwich, 2002; Booth and Ainscow, 1998; Evans and Lunt, 2002; Hansen, 2012; Polat, 2011). Inclusion promises an educational setting design, so that every child can have equal access to education with their full acceptance, regardless of their background information or individual differences. Although not all teaching assistants (TAs) work with pupils with SEND, the enrolment of more pupils with SEND in mainstream classrooms and the successful implementation of inclusion in mainstream schools has led to the increasing employment of TAs at a national and international level (Higgins and Gulliford, 2014). According to the last Department for Education (DfE) statistics, the number of TAs working in England increased more than five times from 50,800 in 1995 to 265,600 in 2016 (Department for Education, 2017). In fact, the number of TAs is equivalent to onefourth of all school employees in England and Wales (Webster et al., 2011). It is considered that support staff make an important contribution to the management of classrooms and decrease teachers' workloads (DfE, 2012; Lee, 2002).

Several studies have reported that, with regards to their skills, knowledge and qualifications, the role of the TA is based upon the idea that TAs can only have a limited pedagogical role, and they can redesign tasks for students with different learning needs and disabilities, instead of doing the duties of qualified class teachers in the classroom and having a full pedagogical role in teaching (DfES, 2003; Blatchford et al., 2009; Webster et al., 2011; Butt and Lowe, 2012; Blatchford, Russell and Webster, 2012a; DfE, 2013a). Moreover, some researchers have highlighted that TAs make a considerable contribution to reducing the class teacher's workload and enlarging the scope of teaching opportunities for their school by supplying one-to-one and small group teaching (Webster et al., 2015).

However, some studies have stated that the participation of TAs in the school workforce causes some unintended consequences in the sense of their inadequate training compared with their job needs (Webster et al., 2011; Giangreco, 2010). The Office for Standards in Education (Ofsted, 2010) have reported that, for the most part of their teaching, TAs are involved in one-to-one or small group activities and work usually with lower-attaining students or those most likely to show problematic behaviours. Several research studies have also shown that TAs often withdraw SEN pupils from their classrooms for specific intervention lessons, thus decreasing the interactions of those pupils with qualified class teachers and with their peers (Causton-Theoharis et al., 2007; Giangreco and Broer, 2005; Giangreco, 2010). Consequently, the students with the most educational needs are being educated by the least qualified staff in the school, and this raises the question over whether this is the most efficient way of deploying TAs in mainstream classrooms. In contrast, the efficient training of TAs could make a 
significant contribution to raising the standards of teaching for pupils with or without SEND.

\section{Research Aims}

In the proposed study I will aim to adopt a particular perspective from which to examine the perceived relationships between TAs' training and their professional role in supporting teaching and learning as a TA.

In doing so, I aim to investigate the training and teaching experiences of TAs in both training colleges and in inclusive classrooms in their first year of professional life, and to investigate the ways in which TAs act according to their understanding of their training and teaching experiences. Through having multiple contacts with the research participants during the one-year TA training programme, I aim to follow the personal and professional changes and challenges of TAs from the beginning until the end of their training. Furthermore, I will seek to find out whether there is a correlation between TAs' personal background information and their teaching ability. Finally, an analysis of the data collection and the strengths and weaknesses of the proposed research will take place.

\section{Research Questions}

Accordingly, in this research I aim to answer the following questions:

Q1. A. In what ways do stakeholders see TAs' training as influencing their personal and professional development?

B. In what ways do stakeholders see TAs' training as influencing their teaching of pupils with SEND in mainstream classrooms?

Q2. To what extent and in what ways do stakeholders see compatibility between what TAs are required to do in their role and what they have learned in TA training?

Q3. Is there a consensus between stakeholders with regards to how they see the TA role?

Q4. Are the differences in the views of the TA role relevant to how TAs carry out their roles?

After doing the literature review and deciding on the research questions, a concept map has been created for the research by going through these questions. A concept map provides schematic information about a researcher's work and makes the research clearer and more understandable to other participants (Novak and Gowin, 1984, p.15). Because of that an explanatory concept map has been drawn for the purposes of this study. 
Figure 1. Conceptual model (concept map) of the links between TA practices and the influences on these in relation to training courses.

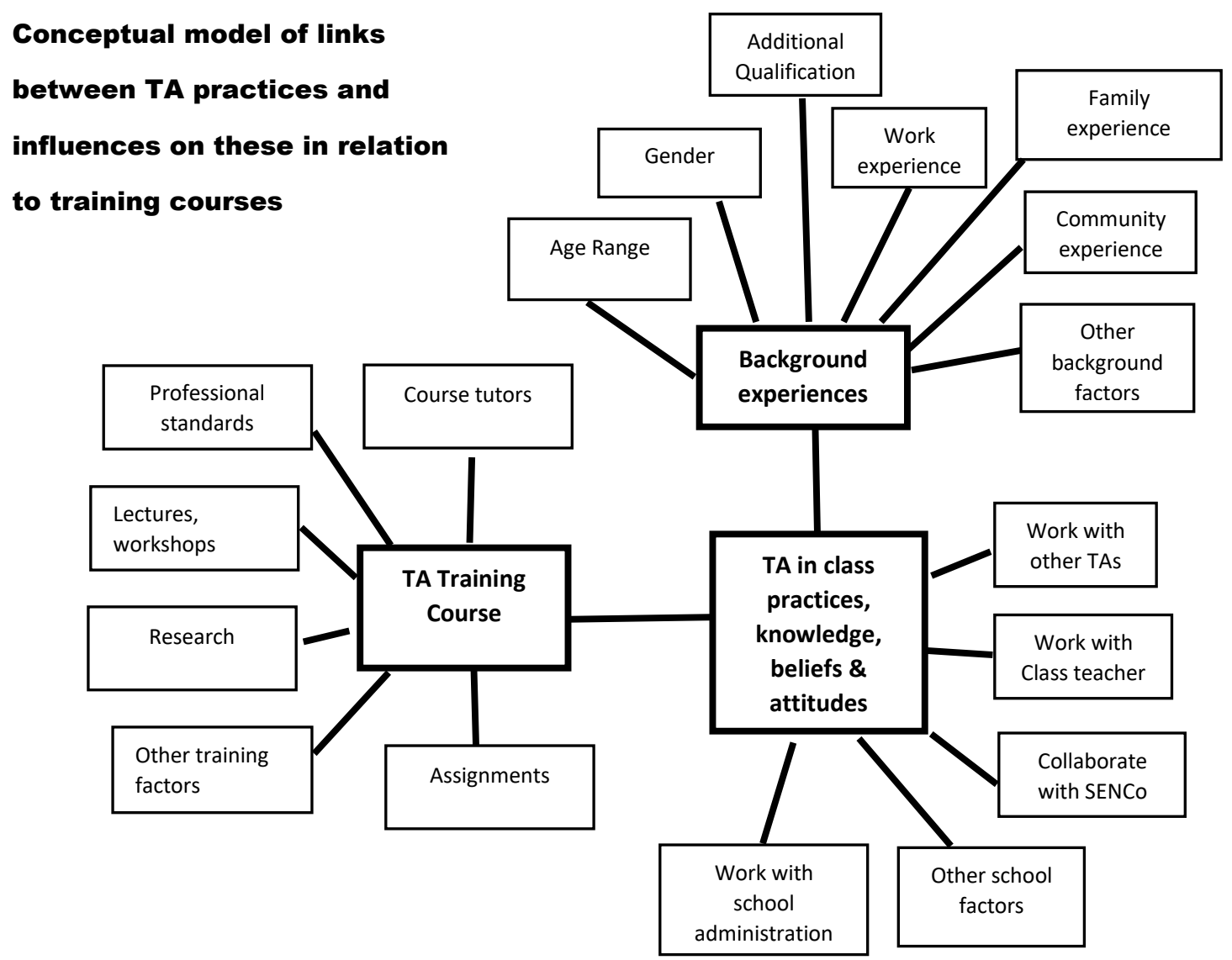

Source: Own creation of conceptual model based on DFM

\section{Methodology}

\section{a. Case study}

It was decided in this exploratory study to use a multiple case study design. For this reason, the purpose of the research and the research questions that have emerged for this purpose indicate that the most appropriate methodology for this research is the case study. A research case may be an individual, a group, a situation or a programme where the researcher is interested in obtaining more specific information and making different interpretations (Merriam, 1998). In this intensive case study, 12 cases will be selected to find the structures, patterns, relationships or contradictions of the findings, in order to find answers to the research questions. Yin (2003) emphasises that the multiple case study research design allows for the collection of very detailed information that cannot be easily obtained by other research designs, and thus it gives the research validity. Exploring the training factors that influence the role of TAs when teaching students with SEND in mainstream classrooms is the focus of this research, hence the use of case 
studies, as Zainal (2017, p.1) puts it, "allows the exploration and understanding of complex issues and it can be considered a robust research method particularly when a holistic, in-depth investigation is required". Moreover, the role of the case study method, which is often described as a tool in social sciences research, becomes even more evident in studies on complex topics in education (Gulsecen \& Kubat, 2006). Since this study involves a focus on complex educational issues, multiple case studies have been chosen as the research method.

In this proposed study, I will conduct the case studies according to their relevance to subject. Since the topic is to explore the perceptions of factors that have influence on the role and professional development of TAs, the researcher will focus on the research of each TA who is both receive training and have teaching. I will examine the real learning and teaching situation of TAs with all its complexities to discover what factors might contribute to their outcomes. To find answers to these complex questions, first observation and then interview methods will be used. During the research, each case will be treated individually to reveal the internal properties of the case in relation to the subject searched, and then cross case conclusions will be drawn to understand the similarities and differences between the cases. In the intended study, each individual case is defined as "an individual in his or her first year in the position of TA in a mainstream school in the government school system of England, while he or she is in formal training for his or her TA role". Individual cases may have similarities to or differences from each other due to different factors, but by combining the data of these individual cases, a better understanding and meaning can be formed, which can offer different possibilities to the researcher (Stake, 2000). In this proposed study, I am aiming to identify the common factors that are thought to influence the teaching of TAs, to reveal significant differences between different cases, and to provide new, rich information from the experiences of TAs. In addition, I am aiming to generate propositions regarding the perceptions of TAs' training efficacy and their role in the classroom. For these reasons, and for the assumptions inherent in the interpretivist framework adopted in the study, the multiple case study approach appears to be the most appropriate investigative strategy to answer the research questions.

\section{b. Theoretical assumptions}

This proposed study is to be conducted in an interpretivist-qualitative framework, and the reason behind the choice of an interpretivist paradigm lies within the nature of the process observed. In this research, I will take training and teaching processes as a central focus, and, as Punch (1998, p.161) highlights, "To understand any process, or any event, act, or group; it is necessary to study the behaviour in its context setting." A fundamental aim of my study, as outlined in the introduction, is interpretation; so, in this research I will adopt an interpretivist methodological framework. Accordingly, education is considered to be a process, and school is a lived experience in this interpretive research (Merriam, 1998). 
This research will feature qualitative data collection, which will be conducted using two research methods: descriptive observations, and semi-structured interviews. George and Bennet (2005) remark that a case study has the main advantage of providing indepth analysis in a particular context and can be beneficial for the researcher when gathering more comprehensive information about their research subject. This twodimensional data collection process also allows the researcher to eliminate, analyse or account for diverse relevant factors, which might possibly have an impact on the elements under investigation (Merriam, 1998). In this study, I will produce an account of the training and teaching activities of TAs with regards to students with SEND through observations, and I will elicit detailed information on these perceptions and presuppositions through the semi-structured interviews.

\section{Design of the study}

The research design (Figure 2) was kept flexible enough to respond to findings in the research process and field information changes that may occur. As a matter of fact, Stake (1995) indicates the need for progressive focusing throughout the research process.

Figure 2. Research Design

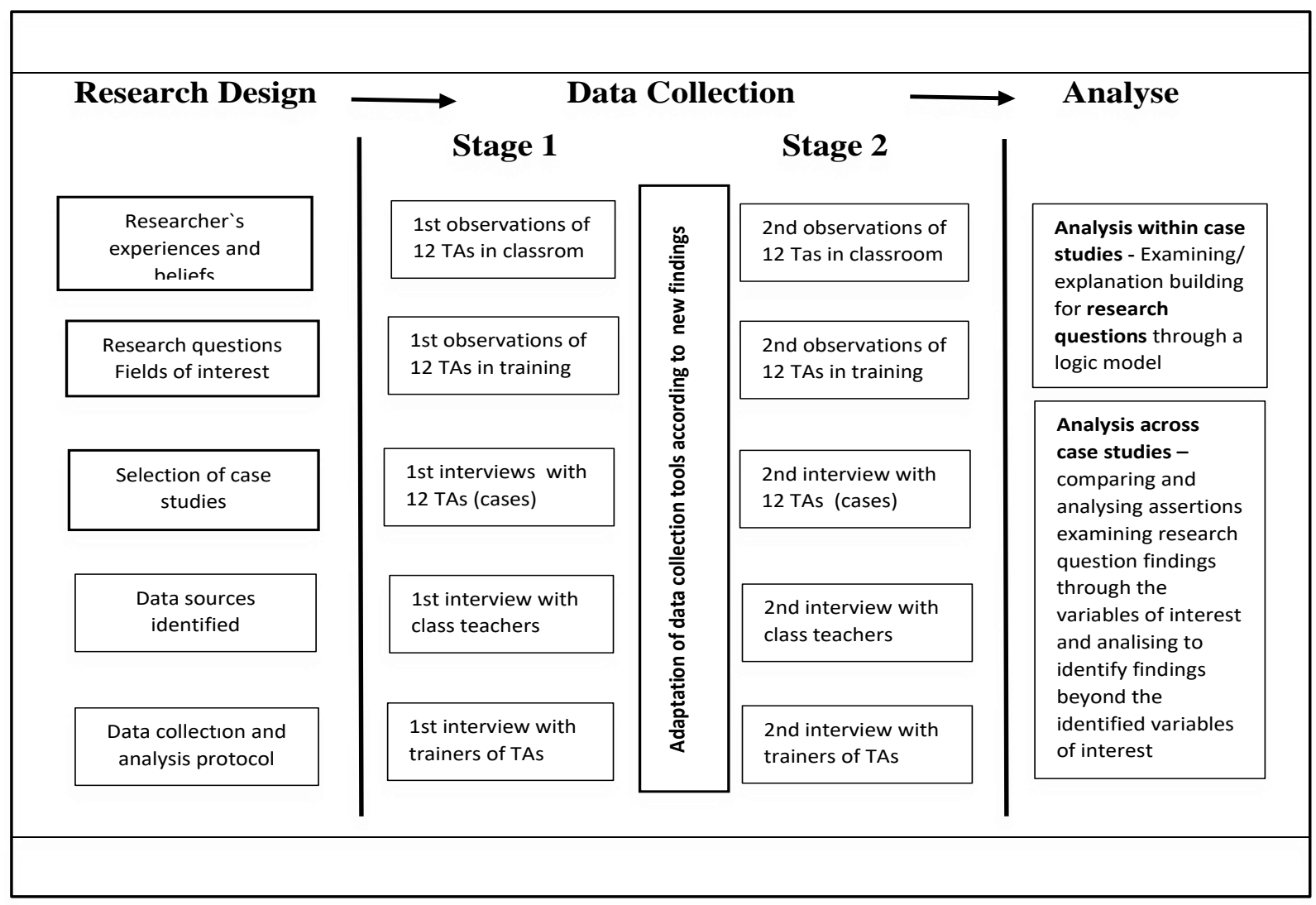

Source: Own creation of Research Design Table 
The research data collection process will be carried out in two stages. I will gather the first phase information in the early stages of the TAs' training courses, and the second phase information will be gathered at the end of the TAs training courses. In this way, I will attempt to show whether the skills, knowledge and efficacy perception of the TAs have changed over the period of the training. The first phase will express the starting knowledge and skill perceptions of the TAs, while the second phase will investigate whether there is a change in their knowledge and skills perceptions. I will also look at whether there is a positive or negative correlation in terms of the perceptions of the TAs between their background information and their teaching knowledge and skills.

\section{Participants}

Participants in each of the 12 cases will be:

- The TA

- The TA's tutor

- The classroom teacher who is the TA's supervisor

\section{Selection of Participants}

The selection of TAs and other participants to be used for the intended study was based on purposeful sampling. Patton (2015) describes purposeful sampling as the method of sampling chosen for a specific purpose, or the selection of a group that fits this purpose. The specific purpose of this intended sampling is to include a maximum variation of TAs with different backgrounds. Therefore, I will ask various institutions and individuals whether they want to participate in the intended study, and the people who will be required to participate in the research will be selected in the most varied manner possible. I will first contact the candidate institutions and individuals by phone and will then have a face to face meeting with those who have a positive opinion towards participation in the research.

I will ask training TAs if they want to participate in the intended study. Each TA will be in their first year of training and will be selected as a case study and purposive sample. In total, 12 TAs will be selected to observe all of the individual differences which are to be examined, besides the training factors of these TAs. I will select 12 participants from the TAs who have volunteered to take part in the research that reflect the maximum variation according to the participants' gender, age group, familial situation, educational level and socio-economic background.

As an example of the diversity of the sample, the participants in this study will include as many males as possible, as most TAs are female. Besides, candidates participating in the research can generally be expected to be in their twenties and unmarried; therefore, I will try to find as many married and child-bearing candidates as possible in 
order for the research to feature participants with maximum variation, to obtain different perspectives and more in-depth knowledge. Additionally, the TAs will be taken from both primary and secondary schools, in order to evaluate whether there is any difference between those levels in terms of their teaching roles and efficacy. The sample will include TAs who are teaching at different grade levels in order to obtain more purposive sampling. For this purpose, I will communicate with TAs from both primary and secondary schools and will try to include an equal number of participants from the TAs who work at both levels. So, although each case (TA) goes through the same training process, do they have different perceptions, and if so, do their placements and individual factors play a role? This will be researched.

\section{Data collection}

\section{a. Observations}

Although the observation method poses risks, such as the researcher being subjective during observation and the observed person performing better than normal, it is an effective method of gathering information in order to be able to inspect where and when activity occurs, and to see directly what people are doing rather than relying on what they say they do (Sapsford and Jupp, 2006, p.59). The naturalistic observation method will be used to look at the behaviours as they occur in their natural setting, with no attempts at intervention on my part (Bordens \& Abbott, 2002). I will seek to observe naturally occurring TA behaviour in the classroom with this data collection method, and this method will also allow for extremely high external validity (Bordens \& Abbott, 2002). I will record my classroom observations simultaneously in my notepad, and the observed person, class, observation date, time, and observation period will be added to each observation record, in order to prevent file confusion that may occur later.

From this point of view, I will observe each participant three times in their work environment in each stage, in order to understand the participants' perspectives better, and to compare the research findings (Mathison, 1988; Merriam, 1998). This three-time naturalistic observation method will also enable me to examine the consistency of behaviours. Observations will be recorded descriptively and will take place in both TAs' training classes and the classroom teaching environment. As the observer, I will sit and remain quiet in the classroom, and will observe the teaching activities carried out by the TAs for the children with or without SEND in each lesson. All observations will be made according to a predefined observation schedule. Each of the non-participant descriptive observations will last approximately 30 minutes in order to obtain a sufficiently long sample, and I will take notes in my notebook.

These observations will be made in colleges where TA students are trained, and in mainstream school classes where they are doing placements and teaching. While the TA training activities and their interactions with TA trainers will be observed at the 
colleges where the TAs are trained, school observations will see the TAs' own work, and their interactions with students and classroom teachers. The first observations will be held during January and February, and the second observations will be held during June and July, at a time convenient to each participant. While the first stage observations will be focused on gathering initial information for the TAs' training and classroom placements, the second observation will include whether the TAs have changed personally and professionally because of their training since the first observation. The observations will be chosen at the most appropriate time for the TAs, TA trainers and supervisors of the TAs in the classroom (mostly classroom teachers), so that I can obtain the most accurate results from the observations.

I will take field notes to record my observations during the training placements and workplace visits and will apply several different observation methods to obtain the required information, such as descriptive, focused and selective observations (Spradley, 2016, p.33; Werner and Schoepfle, 1987). The field notes of the descriptive observations will include the general context of the study location and will include information such as the classroom environment and school climate. Besides this, most of the observations to be made during school and training place visits are planned to be either focused or selective.

\section{b. Interviews}

In terms of academic research, interviews allow a researcher to obtain detailed information about the interviewed individual's feelings, perceptions, opinions and interpretations of his or her own experiences in a communication environment (Fontana and Frey, 2000; Minichiello, Aroni, Timewell and Alexander, 1995). With an in-depth interview, the interviewer focuses on understanding the participants' beliefs, attitudes and other experiences, as well as reports of their own and others' behaviour, and this data collection method involves direct, one-on-one engagement with individual participants (Taylor and Bogdan, 1984). In this proposed study I will seek to gather data from TAs, trainers of TAs and supervising class teachers through in-depth interviews, which will be semi-structured. I will ask open-ended questions to allow each participant to express himself or herself more easily, and to give more detailed information. I will ask questions to each of the participating TAs about how effective their training and other individual factors are on their teaching and professional development, and I will try to gather comprehensive answers from them. Then, to include the diversity of knowledge and different perspectives, the questions asked of the TAs will then be adapted and asked of the TAs' trainers and classroom teachers.

I will conduct interviews with each of the TAs, the classroom teachers who are in the role of supervising the TAs, and the module leaders who are training the TAs in college. Interviews will be conducted in a semi-structured manner, with open-ended questions. Each interview will last approximately 35 minutes, and the audio will be recorded on a 
smartphone. Interviews will take place at the college where the TAs are training, and at the schools where they are undertaking their teaching placements. The questions will encourage discussion, and will enable the TAs, class teachers and TA trainers to share their concerns, ideas and personal experiences of the improvement of TAs during their training.

\section{Data analysis}

\section{a. Observations}

Observation findings will be analysed according to the model of data analysis framed by Miles and Huberman (1994). According to this analysis model, observation findings will be analysed by passing them through data reduction, data display and the drawing of conclusions. This analysis model is schematically shown in Figure 3 below.

Figure 3: Components of Interactive Data Analysis Model

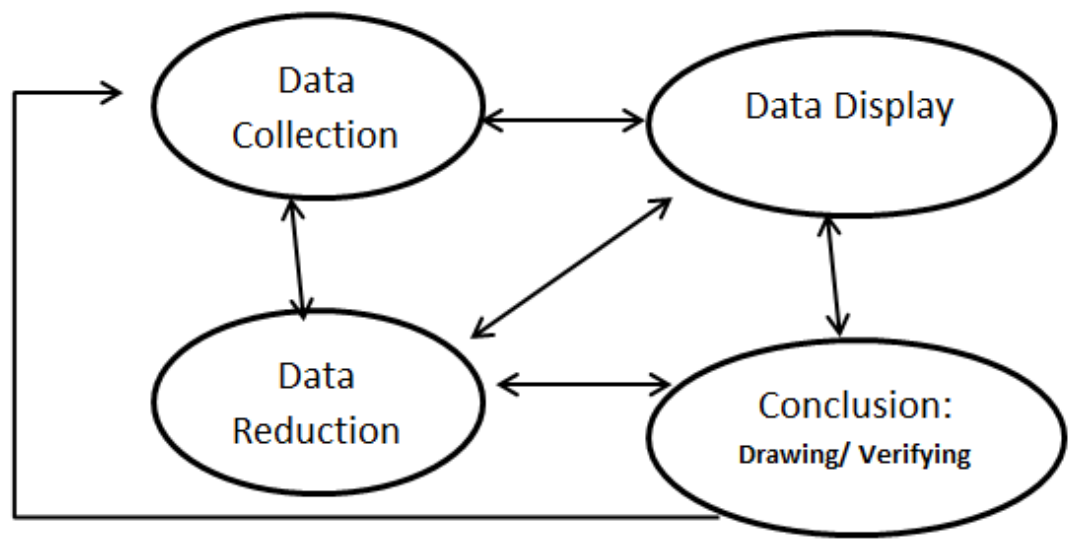

Source: It has been taken from the "Qualitative Data Analysis: An Expanded Sourcebook" (Miles and Huberman, 1994, p.12)

In data reduction's first-level phase, the phrases and sentence phrases recorded in the observations will be aggregated under descriptive concepts and codes. In the secondlevel data reduction phase, similar concepts and codes will be considered as a more comprehensive set, and each will be grouped under one category. If I do not see enough data reduction and simplification to be done at this stage, I will be able to include thirdlevel category coding. The data reduction phase will involve the examination of the time spent on these various tasks, as well as the separation of observation field notes into categories and codes. 


\section{b. Interviews}

I will also apply the stages of data reduction, data display and the drawing of conclusions to the analysis of the interviews. So, the general framework of the model has been established by Miles and Huberman (1994), and the information on this is provided in section $6 \mathrm{a}$. The data reduction phase will be applied so that I am able to find the parts of the interview transcript that serve the research purpose. To make the transcript data more understandable and to divide it into more manageable components at this stage, in the process of simplifying the interview data, a first and second level coding approach will be adopted (Punch, 2013). In the first-level coding phase, the transcript data will be examined in small, separate pieces, and the themes expressed will be determined. During the analysis of these data, each sentence and/or sentence group will be examined and each one will be grouped under a descriptive name.

\section{c. Case analysis}

At this stage, I will analyse all of the information obtained from each case during the first stage and second stage of data collection. After analysing and comparing the results of the observations and interviews for each case separately, the results of these data will be compared with each other, and this comparison will examine the links between the participants' perspective and the observation data. I will analyse the findings in detail in order to maximise the information obtained from each case's findings. I will also observe whether there has been a perception change in the cases (participants) since the first meeting. By combining these observations and interview findings, an overall case study will be created for each case, and each case will have a meaningful internal structure.

\section{d. Cross case analysis}

After all of the cases have been analysed internally and each case's information has been integrated into a holistic structure, I will carry out a cross-case analysis. With the cross-case analysis, data will be analysed for its similarities and diversities around the emerging themes and common features. I will seek to make meaningful conclusions about the themes that arise from the comparison of the data analyses. Together, these analysis methods will provide the means to assess the dimensions of the different findings throughout the full range of variation, because this multi-method approach will provide a more desirable, feasible level of information, and a more complete view (Creswell and Plano Clark, 2007). Because of this cross-case analysis, I will reach the final interpretations and results of the research. 


\section{Conclusion}

\section{a. Strengths}

The aim of this intended study is to collect much detailed information that cannot be easily obtained by other research designs due to the nature of case studies. The data to be collected is normally intended to be richer and deeper than those which can be obtained through other experimental designs. Hereby, my aim in this proposed study is to provide an important and specific contribution to TAs' training and development perceptions in a variety of ways. Firstly, in the review of the academic literature, there was found no other study involving TAs in the field of education and development which examined the perceptions of TAs' personal and professional development at the same time as the time they were training. Secondly, in the intended study, the factors affecting the perceptions of the personal and professional development of TAs will not be limited to their training, but their background information will also be explored.

Moreover, in the analysis of research findings, I will aim to increase the trustworthiness of the research by using the triangulation, member-checking and peer review methods. In addition, in terms of the perception of the factors affecting the development of TAs, besides using TAs as the initial information source, the opinions of classroom teachers who supervise the TAs on their placements and the module leaders of the TAs' training courses will be interviewed, to maximise the reliability of the research findings. Through this proposed study I am also aiming to further the understanding of the perceived influence of individual differences on the professional development of TAs. By looking at the findings, I am particularly aiming to develop proposals on which training factors and which individual factors may contribute more in terms of the professional development of TAs.

\section{b. Limitations}

Although this study is structured very precisely, there are obvious limitations involved. Firstly, the research does not include any longitudinal data to test the training of TAs and other influencing factors on the role of TAs, with a cross-lagged prediction model on whether it is the training of TAs which predicts the TA role, or whether it is the other influencing factors of TAs that predict the role. Secondly, due to the inclusion of 12 case studies, the period of data collection and analysis of those 12 case studies will take a long time, and this will lead to difficulties in terms of conducting the research. In this regard, according to Yin (1984), it is difficult to manage case studies, as too many documents can be produced during these studies.

Moreover, all of the TAs in the study will be drawn from only one regional sample, which will affect the reliability of the information obtained through the research. Each of the 12 TAs to be studied will be taught at different levels and in different classes, and this variety of teaching will influence their teaching effectiveness, which will eventually limit 
the legitimacy of the research findings. The training of TAs is a current issue that is changing along with new practices and approaches, and therefore the research findings may have a limited shelf life in advance of further research.

Clearly, like all other qualitative research methods, I will take into account the verbal information given by the participants and the findings based on those, which will unfortunately lead to a certain level of subjectivity in the study. I will ask the participants who are involved in the research at certain intervals what effect the training and other individual factors have had on their TA role fulfilment, which in turn will push the TAs to think more deeply on this issue and will allow them to respond more sophisticatedly in the interviews.

All in all, this research proposal will represent a forward step towards evaluating the relationship between the perceived influencing factors and the role of TAs teaching pupils with SEND in differentiated classrooms, and this topic will certainly call for further research.

\section{References}

ALBORZ, A., PEARSON, D., FARREL, P. and HOWES, A. (2009). The impact of adult support staff on pupils and mainstream schools: A systematic review of evidence. London: Department for Children, Schools, and Families.

ANDERSON, V. and FINNEY, M. (2008). I am a TA not a PA! Teaching assistants working with teachers. Richards, G. and Armstrong, F. (2008) (Ed), Key Issues for Teaching Assistants: Working in Diverse and Inclusive Classrooms, Routledge.

AVRAMADIS, E. and NORWICH, B. (2002). Teachers' attitudes towards integration / inclusion: a review of the literature. European Journal of Special Needs Education, 17(2), pp.129-147.

BACH, S., KESSLER, I. and HERON, P. (2006). Changing job boundaries and workforce reform: the case of teaching assistants. Industrial Relations Journal, 37(1), pp.2-21.

BALCHIN, N., RANDALL, L. and TURNER, S. (2006). The Coach Consult Method: A model for sustainable change in schools. Educational Psychology in Practice, 22(3), pp.237-254.

BEDFORD, D., JACKSON, C.R. and WILSON, E. (2008). New partnerships for learning: Teachers' perspectives on their developing professional relationships with teaching assistants in England. Journal of In-service Education, 34(1), pp.7-25.

BIGNOLD, W. and BARBARA, J. (2012). Teaching assistants and teacher education in England: meeting their continuing professional development needs. Professional Development in Education, 38(3), pp.365-375. 
BLATCHFORD, P., RUSSELL, A., BASSETT, P., BROWN, P. and MARTIN, C. (2007). The role and effects of teaching assistants in English primary schools (Years 4 to 6) 2000-2003. Results from the Class Size and Pupil-Adult Ratios (CSPAR) KS2 Project. British Educational Research Journal, 33(1), pp.5-26.

BLATCHFORD, P., BASSETT, P., BROWN, P., MARTIN, C., RUSSELL, A. and WEBSTER, R. (2009). Deployment and impact of support staff project. Research Brief.

BLATCHFORD, P., BASSETT, P., BROWN, P., MARTIN, C., RUSSELL, A. and WEBSTER, R. (2011). The impact of support staff on pupils"positive approaches to learning'and their academic progress. British Educational Research Journal, 37(3), pp.443-464.

BLATCHFORD, P., BASSETT, P., BROWN, P. and WEBSTER, R. (2009). The effect of support staff on pupil engagement and individual attention. British Educational Research Journal, 35(5), pp.661-686.

BORDENS, K.S. and ABBOT, B.B. (2002). Research design and methods: A process approach. New York: McGraw-Hill.

BOOTH, T. and AINSCOW, M. eds., 1998. From them to us: An international study of inclusion in education. Psychology Press.

BUTT, R. and LOWE, K. (2012). Teaching assistants and class teachers: Differing perceptions, role confusion and the benefits of skills-based training. International Journal of Inclusive Education, 16(2), pp.207-219.

CAUSTON -THEOHARIS, J.N., GIANGRECO, M.F., DOYLE, M.B. and VADASY, P.F. (2007). The "souschefs" of literacy instruction. Teaching Exceptional Children, 40(1), pp.56-62.

CRESWELL, J.W. and CLARK, V.L.P. (2007). Designing and conducting mixed methods research. Thousand Oaks: Sage Publications.

DEPARTMENT FOR EDUCATION (2017). School workforce in England: November 2016. London: Data Outputs Division, Department for Education, pp.4- 5.

GEORGE, A.L. and BENNETT, A. (2005). Case studies and theory development in the social sciences. Cambridge, Massachusetts: Mit Press.

GIANGRECO, M. (2010). Utilization of teacher assistants in inclusive schools; is it the kind of help that helping is all about? European Journal of Special Needs Education, 25(4), pp.341-345.

GIANGRECO, M.F. and BROER, S.M. (2005). Questionable utilization of paraprofessionals in inclusive schools: Are we addressing symptoms or causes? Focus on autism and other developmental disabilities, 20(1), pp.10-26.

HANSEN, J.H. (2012). Limits to inclusion. International Journal of Inclusive Education, 16(1), pp.89-98. 
HIGGINS, H. and GULLIFORD, A. (2014). Understanding teaching assistant self-efficacy in role and in training: its susceptibility to influence. Educational Psychology in Practice, 30(2), pp.120-138.

MERRIAM, S.B. (1998). Qualitative Research and Case Study Applications in Education. Revised and Expanded from "Case Study Research in Education". San Francisco: Jossey-Bass Publishers.

MILES, M.B. and HUBERMAN, A.M. (1994). Qualitative data analysis: An expanded sourcebook. London: Sage Publications.

PATTON, M. (2015). Qualitative Research \& Evaluation Methods. 4th ed. London: SAGE Publications, pp.264-265.

POLAT, F. (2011). Inclusion in education: A step towards social justice. International Journal of Educational Development, 31(1), pp.50-58.

PUNCH, K.F. (2013). Introduction to social research: Quantitative and qualitative approaches. London: Sage Publications.

SAPSFORD, R. and JUPP, V. (2006). Data Collection and Analysis - SAGE Research Methods. 2nd ed. London: Sage Publications, pp.59.

SPRADLEY, J.P. (2016). Participant observation. Illinois: Waveland Press, Pp.33-34.

STAKE, R.E. (1995). The art of case study research. 1st ed. London: Sage Publications.

STAKE, R.E. (2000). Case Studies. In: DENZIN, N. and LINCOLN, Y. (eds.). Handbook of qualitative research. pp. 435-455.

YIN, R.K. (2003). Case study research: design and methods. Applied social research methods series. Thousand Oaks, CA: Sage Publications.

WEBSTER, R. and BLATCHFORD, P. (2015). Worlds apart? The nature and quality of the educational experiences of pupils with a statement for special educational needs in mainstream primary schools. British Educational Research Journal, 41(2), pp.324-342. 